\title{
Deconstruction of the Ethics of Blood Kinship from the Pespective of a New Ethic of Family Kinship in Wise Children
}

\author{
PANG YANNING
}

\begin{abstract}
Angela Carter's masterpiece, Wise Children, highly controversial as it is, represents a strikingly new perspective on ethics, namely, the family ethic of non-blood kinship. This refers to abandoning the establishment of a family solely on the basis of legitimate blood kinship and constructing a new type of family kinship on the basis of Aristotle's notion of "friendship", rather than on the kinship of marriage and blood. It is through the connection between the characters and constructing the plot that Carter deconstructs the hegemony of blood kinship and rejects the blood-kinship family mode. It can be argued that this newly-constructed system of ethics proposes a new way out for modern people suffering from the predicament of loneliness.
\end{abstract}

Keywords: Angela Carter; Wise Children; ethics of blood kinship; family ethic of non-blood kinship

Angela Carter (1940-1992) was one of the most original and prolific British writers of the late $20^{\text {th }}$ century. The theme of Carter's last novel, Wise Children, is quite different from her previous novels, which leads to constant debates in the literary critical circles. One of the focuses of these debates is family ethics. Critics believe that the novel's ending - the 75-year-old twin sisters accidentally adopting three-months-old twins, which allows them to achieve their dream as mothers - is incredible and puzzling; critics also argue that this "temporary substituted family" in the novel is a redundant arrangement/ending, "the fantastic Utopia incurred by carnival" (Webb 2007: 308-314). In a word, the above comments did not pay enough attention to the new family ethic of non-blood kinship. Only the critic Gamble pointed out in 2009 that in Carter's Wise Children "'family' is something created out of love and choice, not biology or duty”. (Gamble 2009: 189). The author thinks that, although Gamble did not expound on this, it is the revelation of the true theme of the novel. As Nie Zhenzhao, points out, "the essence of literature is the art of ethics, and the value of literature epitomizes the moral edification function of it." (2014: 11) 
Therefore, if we cannot analyse the novel from the perspective of the writer's special family ethics, we cannot understand the essence of the socalled postmodern works of art. In my view, it is through the construction of a connection between the characters and the plot that the novel reveals the crisis of the blood-kinship family and the "friendly" (which is Aristotle's term in Nicomachean Ethics, here "friendship" refers to Aristotle's "friendship", that is, all human affection except for romantic love, such as parent-child love, husband-wife love, love between sisters and brothers, love between relatives, and so on) relationship of "the makeshift family" (Gamble 2009: 189) and constructs a new type of kinship family ethics the kernel of which is questioning the establishment of a family solely on the basis of legitimate blood kinship, breaking into pieces the phantasm of blood kinship and constructing a new type of family kinship, which is spontaneously erected on the basis of "friendship", rather than on the kinship of marriage and blood. In this way, we can replace the mechanical pattern of the family framed by established social conventions.

Personal experience and the cultural structure of the formation of Carter's Ethics

Carter's novel is known for its fantasy, but the novel Wise Children boasts a distinct realistic colouring. Living in a poor area on the left bank of the Thames, song and dance girls called Nora and Dora, or the Chance twin sisters, are the bastards of Sir Melchior - a leading figure of the British theatre who lives on the right bank of the river, in the rich area. Unmarried and pregnant, their young biological mother was abandoned by their biological father and died shortly after her giving birth to the twin sisters. It is the mysterious figures, the nonblood related Grandma Chance and Uncle Peregrine, floating around without a definite residence, who adopt them. But this non-blood related family is full of warmth and affection, and continues to accept new unrelated members, so that the family is constantly growing. During this time, Sir Melchior in the upper social circles has married three ladies, one after another, and has two more daughters and twin sons. But his new children are unrelated to him by blood and thus are not of noble birth, moreover, the genealogy of the entire family, from his grandfather on, is questionable and thus no pure blood relationship can be proven. The Melchior family, superficially legitimate and blood-related, is filled with illegitimacy, incest, hatred, and conspiracy, its family affection has disappeared. It is in this "fable" based on the reality of life that Carter expresses her own avant-garde thinking about the family ethics of non-blood kinship. 
PANG

The formation of Carter's new perspective on kinship family ethics is enormously complex. There are two main reasons for this. On one level, it is Carter's special life experience, on another it is the bias of non-blood kinship ethics in Western culture.

Gamble maintains that "in some senses, Wise Children accommodated 'a very definite shift in her work' she attributed to her changed domestic situation" (Gamble 2009: 180). In 1969, Carter's first marriage crisis launched her trip to Japan, but soon she experienced another family breakup, one of the reasons for which was patriarchal ethics, particularly in Japan. In Japanese culture, the secular power of male parents comes from their ancestors' spirit or divine power, which achieves its operation and implementation through the father-and-son and the husband-and-wife relationship. (Tang Chongnan 2006: 177-179). However, in Carter's personal experience, between her and her father there was a "curious abyss that divides the closest kin..." (Carter 1997a: 28).

Based on this personal experience, Carter found no love in their blood kinship, only authoritativeness. In 1980, Carter regained happiness in her forties by remarrying and giving birth to a child. This first-time mother experience made her experience the intimate kinship out of voluntary affection, thus further reinforcing her negation of blood relationships caused by duty. It is in the love of the child that Carter feels the love of "the other" out of "oneself". This "love" is produced by the "object", is after one's own heart, without prescribing a limit to the "object" outside of "the other" (unlike within the patriarchal paternalism and blood-kinship). Carter wrote in "Notes from Maternity Ward": "Constrained affection; what resentment it will breed, in time... he is doomed to love us, at least for a significant initial period, because we are his parents. The same goes for us. That is life. That's the hell of it." (Carter 1997b: 30-31)

In a review written in 1988, Carter affirmed Rhode's point of view of separating family kinship from blood. Rhode is opposed to employing the cruel biologism to analyse an Oedipal situation, and he thinks it makes no sense to be indignant about Oedipus' behaviour when he killed his father and married his mother. Because, as far as Oedipus is concerned, his biological father and mother are total strangers to him. So, we cannot employ cold-blooded ethics to repress living human nature (Carter 2006a: 202-204). All this conforms to Wise Children's ethical demands.

Carter's view of the new family ethics was strengthened gradually by her individual life experiences, but fundamentally, the basic characteristic of this kind of ethics, which is to get rid of blood relationships to establish a new moral value system, is also restricted by her own culture which can be traced back to the ancient Greek "patricide culture" and the Christian view of abandoning kinship for justice. 
We know that in Hesiod's Theogony, Uranus and Cronus, Cronus and Zeus, the two generations of parent-child relationships, move from an "infanticide mode" to a "patricide cycle mode". Therefore, Western European society broke the interpersonal relationship based on blood in the initial stage of the development of civilization. This kind of "patricide culture" played a crucial role in shaping the cultural structure of later generations. After the $1^{\text {st }}$ century AD, Christianity entered the construction process of Western European culture. This sacred ethic is consistent with the idea of the negative blood relationship of a patricide culture. In the New Testament, Jesus did not recognize his mother and brother in order to comply with the will of God because blood is a dividing factor. Only by loving the Lord can we gain eternal affection. He said: "Anyone who loves his father or mother more than me is not worthy of me; anyone who loves his son or daughter more than me is not worthy of me" (Matthew 10:37). In this way, the concept of "Father's will" as the most important consideration is affirmed in Christianity and the priority status of blood ethics is denied.

To reinterpret such a cultural concept transcending blood and secular relations, Cater in Wise Children promotes a sense of responsibility and goodwill in modern society, trying to establish an emotional community. Here the "non-blood kinship" means not abandoning the most basic link of the human community but expanding the concept of "home", to incorporate the nonblood relationship into the legitimate kinship "home". This broad family ethic stemming from Christianity is conducive to social blending. As Carlyle wrote in Past and Present, "'home' is like a society, social members should be like brothers and sisters, and not just geographical or regional neighbours" (Carlyle 2010: 250).

\section{Revealing the paradox of old blood-kinship family}

The disintegration of the traditional blood-kinship family that Carter depicts is not only a representation of Western cultural ideas, but simultaneously is it descriptive of the entire European social reality. This reality is that in the modern society of Europe, on the one hand, blood family is increasingly falling apart, and on the other hand, blood ties may be a serious hindrance to the possibility of new families to be built.

In the pre-modern society, the community relations generated by traditional reason, emotional reason, were replaced by the instrumental rationality and value rationality generated by modern capitalist society the typical characteristic of which is bureaucracy. In terms of values, the traditional, emotional community relations between people were replaced by calculated and available/use values. 
PANG

Thus, the old family kinships became the empty shell of "love" in the form of blood. But in Carter's opinion, the legal relationship is the external reason for old family's disintegration, the essence is that the blood system hinders the ethics of "love". Blood ties are a common ideological hegemony in our real life, which it is difficult for many to realize, but this has led to a variety of family tragedies. Wise Children reveals such family relationships using allegory.

1. First, according to the provisions of the old blood-kinship family, many children whose parents are not married are faced with the dilemma of being abandoned, with their birth identity withheld. The birth of the Chance twin sisters at the beginning of the novel and the three-months-old twin babies at the end are mutual reflections. In the repeated image of twin babies, Carter poses the problem: it is not the parents, but the cold-blooded system, that really abandons the child.

2. In the old family kinship mode there may be a lack of affection leading to hatred between family members without cause or reason, leaving only the empty shell of blood. Under Carter's pen, the blood-kinship family members not only show no love, they stage ceaselessly the tragedy of mutual hatred and suffering. Moreover, Carter also depicts blood-kinship family members scrambling for money and power with each other. "Incest" relationships are another possible cause of tragedy within the family. Only in modern times have such pre-modern blood-kinships become illegal. However, the blood-kinship mode has long been the only legal family construction. After entering the modern industrial society, the family is no longer a production unit, the huge organizations of blood relationships have increasingly tended to collapse and have been replaced by the "nuclear family". But, blood-kinship as the only way to form a family has never disappeared. According to Foucault, we live in a relationship world with rather scarce systems. Although there are some basic relationships in marriage and family, we should diversify the existing interpersonal relationships which had been institutionalized by law. (Foucault 1982: 38) The breaking of the blood hegemony, and recognition of the validity of the non-blood kinship family will make a new type of interpersonal relationship possible. As Carlyle said, eliminating the opposition between society and family, and turning society into family enables members of the society to have family love, so as to construct an affective "community". (Carlyle 2010: 17-19)

The ideal construction of a new type of non-blood family kinship

In Wise Children, in addition to revealing the paradoxes of old blood relationships, Carter also highlights true affection in the new type of non-blood kinship. 
First, new families enable those people made homeless by the loss of blood ties regain a home and a family. Dora, the narrator, says: "It is a characteristic of human beings, one I've often noticed, that if they don't have a family of their own, they will invent one." (Carter 2006b: 165) Here, Carter puts the emphasis on the importance of family. The family is the smallest social unit, so the importance of family is very remarkable. Carter breaks the convention of establishing a family by relying solely on the blood relationship between parents and children and contends that the "discoverer" is the foster parent. (That is to say, the discoverer of children can raise them.) Not only can parents adopt non-blood-related children, but also children can "adopt" parents without any blood relationship to them. The beginning and end of the novel echo each other: at the beginning of the novel, the Chance sisters are discovered and adopted by Mrs. Chance in her old age (no blood relationship); at the end of the novel, the twin sisters in their old age adopt a pair of twins with no certain identity and so acquire children of their own to achieve their dream of having a family. Gamble also pointed out: "It's finders' keepers as far as children in this novel are concerned." (Gamble 2009: 189) Nora and Dora make clear that "Grandma raised us, not out of duty, or due to history, but because of pure love, it was a genuine romance, she fell in love with us the moment she clapped her eyes on us." (Carter 2006b: 12)

Secondly, "fraternity" in the new type of family ethics surpasses the blood relationship. Fraternity or Aristotle's "friendship" is essential in a family, but it is neglected in the old family mode. Just as what Cicero said in De Amicitia, Scipio's Dream: "though the relation of mutual benefit is the property, of friendship it has yet another cause; more sacred and more noble, and derived more genuinely from the very nature of man [...] Friendship, therefore, springs from nature rather than from need, - from an inclination of the mind with a certain consciousness of love rather than from calculation of the benefit to be derived from it." Therefore, the true "friendship" is eternal. (Cicero 1887: 17-18) In the new type of family of the Chance twin sisters "affiliation" triumphs over "blood relationship", "nurture" triumphs over "inherited"; all these subvert the human relationships and principles of "blood is thicker than water".

Carter wrote in her novel that their adopted mother treated the twin sisters as their biological mother would, she "cuddled us. She lullabied us, she fed us. She was our air-raid shelter; she was our entertainment; she was our breast." (Carter 2006b: 29). After her death "Grandma" left them the house she had bought, "she left us everything, we owe her everything and the older we grow, the more like her we become. Triumph of nature over nurture." (Ibid.28) They also loved their adopted father Uncle Peregrine, who "was so much beloved by us and behaved so much more fatherly to us, not to mention paying most of the 
PANG

bills, that I know I need to claim him as something more than Uncle." (Ibid. 17) They even gave their affection to their stepmother, with the nickname of "Wheelchair": "We've been storing Wheelchair in the basement for well-nigh thirty years. We've got quite attached to her. Earlier on, Nora used to take her out shopping, give her some fresh air". (Ibid. 7) They also pushed her to the front of the TV to watch her favourite commercials, and they cared for her as if she were an old child. (Ibid. 8)

In a word, the three generations of the family reveal the interpretation of a complicated and reverse dislocation of the relationship between the characters which are a combination of legal but non-blood relationships, kinship but nonblood relationships, illegal blood relationships, and blood relationships without affection. Thus, Carter supports the argument that this newly-constructed ethics system proposes a solution for modern people suffering from the predicament of loneliness.

\section{Pang Yanning}

p_yanning@126.com

Shandong University of Science and Technology

D18-4-201 Shanhai Garden

579 Qianwangang Road, Qingdao Economic \& Technical Development Zone Qingdao

Shandong Province 266590

P.R. CHINA

\section{Works Cited}

Carlyle, T. 2010. Past and Present. Ed. Henry Duff Traill. Cambridge: Cambridge University Press.

Carter, A. 1997a. Sugar Daddy. - A. Carter, Shaking A Leg. London: Chatto \& Windus, 28-29.

Carter, A. 1997b. Notes from a Maternity Ward. - A. Carter, Shaking A Leg. London: Chatto \& Windus, 30-31.

Carter, A. 2006a. Expletives Deleted. London: Vintage Books.

Carter, A. 2006b. Wise Children. London: Vintage Books.

Cicero, M. T. 1887. De Amicitia, Scipio's Dream. Produced by Ted Garvin, Charles Franks \& the Distributed Proofreaders Team. Trans., with an Introduction and Notes by Andrew P. Peabody. Boston: Little, Brown, and Co.

Foucault, M. 1982. The Social Triumph of the Sexual Will. Conversation with Gilles Barbedette. - Christopher Street, 64, 36-41.

Gamble, S. 2009. Angela Carter: A Literary Life. New York: Palgrave Macmillan. 
Deconstruction of the Ethics of Blood Kinship

Nie Zhenzhao. 2014. Ethical Literary Criticism: On Fundamental Function and Core Value of Literauture. - Foreign Literature Studies, 4, 8-13.

[Tang Chongnan. 2006. Japanese Culture and Modernization. Shenyang: Liaohai Press.] = 汤重南: 《日本文化与现代化》, 沈阳: 辽海出版社, 2006年。=

Webb, K. 2007. Seriously Funny: Wise Children. - L. Sage, ed., Flesh and the Mirror: Essays on the Art of Angela Carter. London: Virago Press, 308-314. 